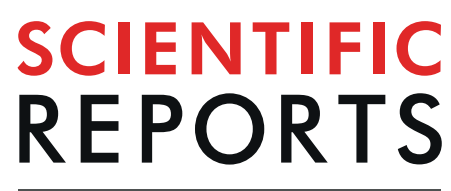

natureresearch

\title{
Large and tunable magnetocaloric effect in gadolinium-organic framework: tuning by solvent exchange
}

\author{
Vladimír Zeleňák ${ }^{1 *}$, Miroslav Almáši ${ }^{1}$, Adriána Zeleňáková ${ }^{2}$, Pavol Hrubovčák ${ }^{2}$, \\ Róbert Tarasenko ${ }^{2}$, Sandrine Bourelly ${ }^{3} \&$ Philip Llewellyn ${ }^{3}$
}

Magnetic properties of three variants of MOF-76(Gd), $\left\{\left[\mathrm{Gd}(\mathrm{BTC})\left(\mathrm{H}_{2} \mathrm{O}\right)\right] \cdot \mathrm{G}\right\}_{n}(\mathrm{BTC}=$ benzene1,3,5-tricarboxylate, $G=$ guest molecules) were investigated by static susceptibility, isothermal magnetization and specific heat capacity measurements. In the study we used as synthesized MOF76(Gd)-DMF (1) (G = DMF = dimethylformamide), containing DMF molecules in the cavity system, compound MOF-76(Gd) (2), activated complex without solvents in the cavities and water exchanged sample MOF-76(Gd)- $\mathrm{H}_{2} \mathrm{O}$ (3). A pronounced change in the magnetic entropy was found near the critical temperature for all three compounds. It was shown, that magnetic entropy change depends on the solvatation of the MOF. The highest value entropy change, $\Delta S_{\text {Mpk }}(T)$ was observed for compound 2 $\left(\Delta \mathrm{S}_{\mathrm{Mpk}}(\mathrm{T})=42 \mathrm{~J} \mathrm{~kg}^{-1} \mathrm{~K}^{-1}\right.$ at $1.8 \mathrm{~K}$ for $\left.\Delta \mathrm{H}=5 \mathrm{~T}\right)$. The $\Delta \mathrm{S}_{\mathrm{Mpk}}(\mathrm{T})$ for the compounds 1,2 and 3 reached $81.8,88.4$ and $100 \%$ of the theoretical values, respectively. This suggests that in compound 3 $\mathrm{Gd}^{3+} \ldots \mathrm{Gd}^{3+}$ antiferromagnetic interactions are decoupled gradually, and higher fields promote a larger decoupling between the individual spin centers. The observed entropy changes of compounds were comparable with other magnetic refrigerants proposed for low-temperature applications. To study the magnetothermal effect of 2 (the sample with largest $-\Delta S_{\mathrm{Mpk}}$ ), the temperature-dependent heat capacities $(C)$ at different fields were measured. The value of magnetic entropy $S$ obtained from heat capacities $\left(39.5 \mathrm{~J} \mathrm{~kg}^{-1} \mathrm{~K}^{-1}\right.$ at $1.8 \mathrm{~K}$ for an applied magnetic field change of $5 \mathrm{~T}$ ) was in good agreement with that derived from the magnetization data $\left(42 \mathrm{~J} \mathrm{~kg}^{-1} \mathrm{~K}^{-1}\right.$ at $\left.1.8 \mathrm{~K}\right)$.

Increase in energy demand in almost all areas of human activity necessitates its careful and properly managed use. Therefore, one of the greatest challenges on mankind in the $21^{\text {st }}$ century relies upon the increasing the efficiency in energy utilization. Particularly, energy demand for cooling is the fastest growing and thus his efficiency can save a lot of financial sources. Energy efficient cooling can also contribute to reduction of carbon trace and green gas emissions like $\mathrm{CO}_{2}$, since most of electricity is still produced by burning of fossil fuels.

One of the promising technologies, that enable cooling with higher environmental and economic efficiency is technology based on the magnetocaloric effect (MCE). This technique is more advantageous than conventional gas compression (vapor-cycling technologies) ${ }^{1,2}$. MCE is $20-50 \%$ more efficient, than conventional gas compression $^{3}$. The MCE can be described as the change of the magnetic entropy and adiabatic temperature in response to a change in the applied magnetic field and can be exploited for magnetic refrigeration in a process known as adiabatic demagnetization $^{4,5}$. The magnitude of the MCE of a magnetic material is characterized by $\Delta S_{M}$, the isothermal magnetic entropy change, and $\Delta \mathrm{T}_{\mathrm{ad}}$, the adiabatic temperature change.

From synthetic point of view, one of the effective strategies to design materials with a high MCE is utilization of isotopic $\mathrm{Gd}^{3+}$ ion with seven unpaired $4 \mathrm{f}$ electrons and the maximum entropy $\left(109.9 \mathrm{~J} \cdot \mathrm{kg}^{-1} \cdot \mathrm{K}^{-1}\right)$. Different kinds of gadolinium-based materials have attracted interest for MCE, including discrete molecules multinuclear metal clusters (molecular nanomagnets) or materials with extended structures $(1 \mathrm{D} \rightarrow 3 \mathrm{D})$ with $\Delta \mathrm{S}_{\mathrm{m}}$ values from 1.9 to $50.1 \mathrm{~J} \cdot \mathrm{kg}^{-1} \cdot \mathrm{K}^{-1}$ under applied field change of $7 \mathrm{~T}^{6-11}$. One subgroup of materials with $3 \mathrm{D}$ extended structures

${ }^{1}$ Institute of Chemistry, Faculty of Science, P.J. Šafárik University in Košice, Moyzesova 11, SK-041 54, Košice, Slovakia. ${ }^{2}$ Institute of Physics, Faculty of Science, P.J. Šafárik University in Košice, Park Angelinum 9, SK-040 01, Košice, Slovakia. ${ }^{3}$ Aix-Marseille University, CNRS, MADIREL, F-13397, Marseille 20, France. *email: vladimir. zelenak@upjs.sk 
are metal-organic frameworks (MOFs), also known as porous coordination polymers. These materials perform superior functional properties and application potential in gas storage, separation, heterogeneous catalysis ${ }^{12-22}$, while their magnetocaloric characteristics have rarely been scrutinized ${ }^{23-25}$.

In MOF compounds, the solvatation state can lead to crystal phase transition and can influence the distances between magnetic metal centers, and consequently also their magnetic properties and MCE. Therefore, the aim of our work is to investigate, how the MCE in MOFs can be influenced by the solvent exchange. For the study we have used gadolinium form of metal-organic framework MOF- $76^{26}$. This compound combines the qualities of isolated paramagnetic $\mathrm{Gd}^{3+}$ centers and the robust framework with strong covalent bond connections in the three dimensions.

\section{Methods}

All chemicals used in the synthesis were of the highest available purity as purchased from Sigma-Aldrich Company and used without further purification.

Synthesis. As synthesized sample MOF-76(Gd)-DMF was prepared according to procedure described in $^{26}$. Activated sample, $\{[\mathrm{Gd}(\mathrm{BTC})]\}_{\mathrm{n}}$, without DMF and $\mathrm{H}_{2} \mathrm{O}$ solvents in the cavity system was prepared by heating of as synthesized complex at $400^{\circ} \mathrm{C}$ in an oven and the sample was denoted as MOF-76(Gd). Water exchanged sample MOF-76(Gd)- $\mathrm{H}_{2} \mathrm{O}$ with formulae $\left\{\left[\mathrm{Gd}(\mathrm{BTC})\left(\mathrm{H}_{2} \mathrm{O}\right)\right] \cdot 4 \mathrm{H}_{2} \mathrm{O}\right\}_{\mathrm{n}}$ was prepared from activated form by its dispersion in distilled water. Elemental and ICP-MS analyses for compounds: MOF-76(Gd)-DMF, $\mathrm{Gd}_{1} \mathrm{C}_{12} \mathrm{H}_{12} \mathrm{~N}_{1} \mathrm{O}_{8}$ (455.48 $\mathrm{g} \mathrm{mol}^{-1}$ ): calculated: Gd, 34.52\%; C, 31.64\%; H, 2.66\%; N, 3.08\%; found: Gd, 34.38\%; C, 31.87\%; H, 2.56\%; $\mathrm{N}, 3.15 \%$; MOF-76(Gd), $\mathrm{Gd}_{1} \mathrm{C}_{9} \mathrm{H}_{3} \mathrm{O}_{6}\left(364.37 \mathrm{~g} \mathrm{~mol}^{-1}\right)$ : calculated: $\mathrm{Gd}, 47.16 \%$; $\mathrm{C}, 29.67 \% ; \mathrm{H}, 0.83 \%$; found: $\mathrm{Gd}$, 47.24\%; C, 29.56\%; H, 0.87\%; MOF-76(Gd)- $\mathrm{H}_{2} \mathrm{O}, \mathrm{Gd}_{1} \mathrm{C}_{9} \mathrm{H}_{13} \mathrm{O}_{11}\left(454.44 \mathrm{~g} \mathrm{~mol}^{-1}\right)$ : calculated: $\mathrm{Gd}, 34.60 \%$; , 23.79\%; H, 2.88\%; found: Gd, 34.77\%; C, 23.58\%; H, 2.94\%. For detailed information about IR spectra and thermal stability of the samples see Tables S1 and S2, respectively.

Elemental and ICP-MS analyses. The elemental analysis was performed with CHNOS Elemental Analyzer vario MICRO from Elementar Analysensysteme $\mathrm{GmbH}$ with sample weight approximately $2 \mathrm{mg}$. The amount of gadolinium(III) in prepared compound was determined in atmosphere of argon on ICP-MS 7700 instrument developed by Agilent Technologies.

Infrared spectroscopy. IR spectra of the compounds were recorded in the form of $\mathrm{KBr}$ pellets with complex/KBr mass ratio $1 / 100$ and using a Nicolet 6900 spectrometer in the wavenumber range $4000-400 \mathrm{~cm}^{-1}$. Before IR measurements $\mathrm{KBr}$ was dried at $700^{\circ} \mathrm{C}$ for $3 \mathrm{~h}$ in an oven and cooled in desiccator. All spectra were collected with a resolution of $4 \mathrm{~cm}^{-1}$ by collecting 32 scans for a single spectrum. The in-situ heating IR spectra (HT-IR) were measured using Thermo Smart Proteus equipment in temperature range $25-400^{\circ} \mathrm{C}$ with heating rate $5^{\circ} \mathrm{C} \cdot \mathrm{min}^{-1}$. The spectra were measured with $10^{\circ} \mathrm{C}$ step after $1 \mathrm{~min}$. standing of the sample at desired temperature.

Thermogravimetry (TG). The TG/DTG (DTG = derivate thermogravimetry) and DTA (differential thermal analysis) measurements were carried out using the Netsch 409 PC instrument under dynamic conditions with a heating rate of $10^{\circ} \mathrm{C} \cdot \mathrm{min}^{-1}$. The mass of the samples was within the $20-30 \mathrm{mg}$. The samples have been heated under air atmosphere with flow rate $20 \mathrm{~cm}^{3} \cdot \mathrm{min}^{-1}$ in the temperature range from 30 to $900^{\circ} \mathrm{C}$.

High-energy powder X-ray diffraction (HEPXRD). HEPXRD measurements were carried out at BW5 wiggler beamline of DORIS positron storage ring in DESY (Deutches Elektronen Synchrotron, Hamburg, Germany). The spectra were measured at room temperature and during in-situ heating (HT-HEPXRD) up to $600^{\circ} \mathrm{C}$ under the conditions as described $\mathrm{in}^{27}$.

Magnetic susceptibility measurements. Temperature dependence of molar susceptibility was obtained by SQUID based magnetometer MPMS 5XL (Quantum Design) in the temperature range 1.8-300 K on three samples MOF-76(Gd)-DMF, MOF-76(Gd) and MOF-76(Gd)- $\mathrm{H}_{2} \mathrm{O}$ in both regimes ZFC/FC (zero field cooled and field cooled regimes) in magnetic field $100 \mathrm{mT}$. The powder specimens (20.6 $\mathrm{mg}$ for MOF-76(Gd)-DMF, $20.2 \mathrm{mg}$ for MOF-76(Gd), and $17.8 \mathrm{mg}$ for MOF-76(Gd)- $\mathrm{H}_{2} \mathrm{O}$ ) were fixed in a gelatine capsule and the capsule was held by a straw. The signal contribution of empty gel cap and the straw was subtracted from the total signal. Also, the obtained data were corrected for the diamagnetic contribution using Pascal's constants.

Heat capacity measurements. The specific heat capacity was measured using the option in PPMS (Quantum Design) at the constant pressure, under external magnetic fields 0-9 T and in conventional temperature range $2-55 \mathrm{~K}$ using ${ }^{4} \mathrm{He}$ refrigerator and in the temperature range $0.4-2 \mathrm{~K}$ using ${ }^{3} \mathrm{He}$ insert. The contribution of the addenda was measured and subtracted from the total specific heat data. The powder samples were fixed to a sample platform using grease Appiezon N.

\section{Results and Discussion}

Structure, morphology and mechanical properties. Microporous isostructural lanthanide-based MOFs of composition $\left\{\left[\mathrm{Ln}(\mathrm{BTC})\left(\mathrm{H}_{2} \mathrm{O}\right)\right] \cdot \mathrm{G}\right\}_{\mathrm{n}}$ or MOF-76(Ln) $(\mathrm{Ln}=$ lanthanide, BTC = benzene-1,3,5-tricarboxylate, $\mathrm{G}=$ guest molecules) ${ }^{12-25}$ represent a class of 3D transformable frameworks, which exhibit permanent porosity and high thermal stability. In the study we used three compounds: compound $\mathbf{1}$ - as synthesized MOF-76(Gd)-DMF (DMF = dimethylformamide), containing DMF molecules in the cavity system; compound 2 - MOF-76(Gd) activated complex without solvents in the cavities; and compound 3 - water exchanged sample MOF-76(Gd)- $\mathrm{H}_{2} \mathrm{O}$. As synthesized sample MOF-76(Gd)-DMF, i.e. sample with the formulae $\{[\mathrm{Gd}(\mathrm{BTC})$ 

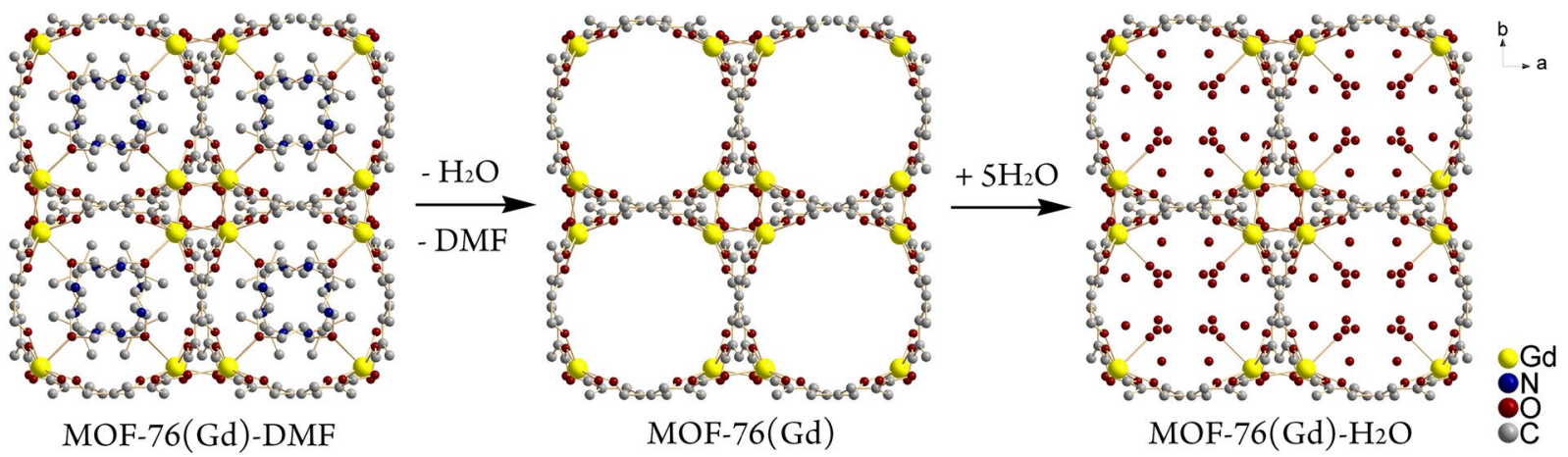

Figure 1. A view of the structures of MOF-76(Gd)-X samples and solvent exchange process $(\mathrm{X}=\mathrm{DMF}-$ compound $1, X=$ no solvent - compound 2, or $X=\mathrm{H}_{2} \mathrm{O}$ - compound 3). Hydrogen atoms are omitted for clarity purposes.

$\left.\left.\left(\mathrm{H}_{2} \mathrm{O}\right)\right] \cdot \mathrm{DMF}\right\}_{\mathrm{n}}$, was prepared according to procedure described in ${ }^{26}$. The desolvated sample MOF-76(Gd), sample with the formulae $\{[\mathrm{Gd}(\mathrm{BTC})]\}_{\mathrm{n}}$, was obtained after heating of MOF-76(Gd)-DMF at $400^{\circ} \mathrm{C}$ in oven for $3 \mathrm{hrs}$. MOF-76(Gd) $-\mathrm{H}_{2} \mathrm{O}$ was prepared from MOF-76(Gd) by its dispersion in distilled water. Water exchanged sample MOF-76(Gd)- $\mathrm{H}_{2} \mathrm{O}$ with formulae $\left\{\left[\mathrm{Gd}(\mathrm{BTC})\left(\mathrm{H}_{2} \mathrm{O}\right)\right] \cdot 4 \mathrm{H}_{2} \mathrm{O}\right\}_{n}$ was prepared from MOF-76(Gd) by its dispersion in distilled water. The scheme of the preparation of the compounds 1-3 and the view of their crystal structures along $c$ crystallographic axis is shown in Fig. 1.

The crystal structures of MOF-76(Gd)-X (X = DMF - compound 1, no solvent - compound 2, or $\mathrm{H}_{2} \mathrm{O}$ - compound 3 ) are built from $\mathrm{Gd}(\mathrm{III})$ ions connected via carboxylate groups of $\mathrm{BTC}^{3-}$ linker giving of one-dimensional left handed helical chains propagating along $c$ axis. In the $1 \mathrm{D}$ chains, each $\mathrm{Gd}^{3+}$ ion has two neighboring $\mathrm{Gd}^{3+}$ ions at the distances of $4.718 \AA$ for MOF-76(Gd)-DMF, $4.296 \AA$ for MOF-76(Gd) and $4.326 \AA$ for MOF-76(Gd)- $\mathrm{H}_{2} \mathrm{O}$. Connection of $\mathrm{Gd}(\mathrm{III})$ and $\mathrm{BTC}^{3-}$ led to formation of a $3 \mathrm{D}$ rod-packing framework with $1 \mathrm{D}$ sinusoidally-shaped channels of size about $6.6 \times 6.6 \AA^{2}$ along the $c$ axis. The $\mathrm{Gd}^{3+} \ldots . \mathrm{Gd}^{3+}$ distances between $\mathrm{Gd}^{3+}$ ions in neighboring $1 \mathrm{D}$ chains are much longer, being in the range 8-11 $\AA$. In the prepared compounds, the cavity system is filled with $\mathrm{DMF} /$ water as guest molecules (sample MOF-76(Gd)-DMF, compound 1), water (sample MOF-76(Gd)- $\mathrm{H}_{2} \mathrm{O}$, compound 2) or cavity system is empty (sample MOF-76(Gd)) (see Fig. 1).

Solvent removal/exchange and thermal stability of the samples were studied by combination of thermogravimetric analysis (TGA, Fig. S1 and Table S1 in ESI), infrared spectroscopy of the samples pre-heated to different temperatures (FT-IR, Fig. S2 and Table S2 in ESI), and high-energy powder X-ray diffraction measured during in-situ heating (HEPXRD, Fig. S3 in ESI). Based on TGA it was shown, that the desolvatation process in the samples MOF-76(Gd)-DMF and MOF-76(Gd)- $\mathrm{H}_{2} \mathrm{O}$ takes place in temperature range $80-400^{\circ} \mathrm{C}$ upon removal solvents from the structure cavities and water molecule coordinated to $\mathrm{Gd}^{3+}$ ion. For the sample MOF-76(Gd)-DMF, i.e. $\left\{\left[\mathrm{Gd}(\mathrm{BTC})\left(\mathrm{H}_{2} \mathrm{O}\right)\right] \cdot \mathrm{DMF}\right\}_{\mathrm{n}}$, the removal of $1 \mathrm{H}_{2} \mathrm{O}$ and $1 \mathrm{DMF}$ molecule was accompanied by mass loss $20.89 \%$ (calcd. $20.00 \%$ ) and for the sample MOF-76(Gd)- $\mathrm{H}_{2} \mathrm{O}$, i.e. $\left\{\left[\mathrm{Gd}(\mathrm{BTC})\left(\mathrm{H}_{2} \mathrm{O}\right)\right] \cdot 4 \mathrm{H}_{2} \mathrm{O}\right\}_{\mathrm{n}}$ the release of 5 moles $5 \mathrm{H}_{2} \mathrm{O}$ was accompanied by mass loss $20.18 \%$ (calcd. 19.82\%). The TG curve of MOF-76(Gd) (see Fig. S1 in ESI) remains unchanged up to $600^{\circ} \mathrm{C}$, indicating that all the solvate molecules, have been removed. The FT-IR spectra of the samples MOF-76(Gd)-DMF and MOF-76(Gd)- $\mathrm{H}_{2} \mathrm{O}$ treated at different conditions also confirm the gradual release of guest molecules, $\mathrm{H}_{2} \mathrm{O}$ and DMF (see Fig. S2 in ESI). HEPXRD pattern of prepared MOF-76(Gd)-DMF measured during in-situ heating (Fig. S3 in ESI) shows two distinct structural changes in temperature range $25-600{ }^{\circ} \mathrm{C}$. Starting from the as-synthesized sample the most relevant changes in the patterns were observed at $140^{\circ} \mathrm{C}$ and $320^{\circ} \mathrm{C}$. The framework started to transform after heating to $140^{\circ} \mathrm{C}$ due to transformation of crystallographic system from tetragonal to monoclinic. Subsequent heating to $320^{\circ} \mathrm{C}$ resulted in minor shifts of the peak positions. Upon heating to higher temperatures crystal structure transformed back to tetragonal system. The HEPXRD patterns of the compounds 1-3 confirmed their crystallinity and structural integrity and are displayed as inset of Fig. S3 in ESI. Rietveld analysis of the patterns confirmed small structural changes and showed, that the presence or absence of the solvents in the cavity system have a significant influence on the Gd...Gd distances with the values of $4.718 \AA$ for MOF-76(Gd)-DMF, $4.296 \AA$ for MOF-76(Gd) and $4.326 \AA$ for MOF-76(Gd)- $\mathrm{H}_{2} \mathrm{O}$.

Porosity and porous structure of sample MOF-76(Gd), obtained after the solvent removal was also studied by $\mathrm{CO}_{2}$ and $\mathrm{CH}_{4}$ adsorption and measurement of adsorption enthalpies. The difference between the $\mathrm{CO}_{2}$ and $\mathrm{CH}_{4}$ adsorbed is weak. The energetic profiles during the adsorption on the surface and the filling of the porosity (slightly increasing for $\mathrm{CO}_{2}$ and quite constant for $\mathrm{CH}_{4}$ ) reveal an energetically homogeneous surface (see Fig. S4 in ESI).

Magnetic properties. The inverse magnetic susceptibility versus temperature (see Fig. S5 in ESI) perfectly follows the Curie-Weiss law and a linear fit for temperature $10-300 \mathrm{~K}$ gives values of $\Theta=1.54 \mathrm{~K}$ for MOF-76(Gd)-DMF, $\Theta=-6.23 \mathrm{~K}$ for MOF-76(Gd), and $\Theta=-5.58 \mathrm{~K}$ for MOF-76(Gd)- $\mathrm{H}_{2} \mathrm{O}$. No difference between the magnetic response of the field cooled (FC) and zero-field-cooled (ZFC) magnetic regimes in studied compounds was observed, indicating no transition to the long-range ordered state. The very weak ferromagnetic interaction (FM) in compound MOF$76(\mathrm{Gd})$-DMF was indicated by a low positive value of $\Theta$. In opposite, the presence of antiferromagnetic exchange interaction (AFM) between $\mathrm{Gd}^{3+}$ ions was evidenced from the negative values of $\Theta$ in complexes MOF-76(Gd) 

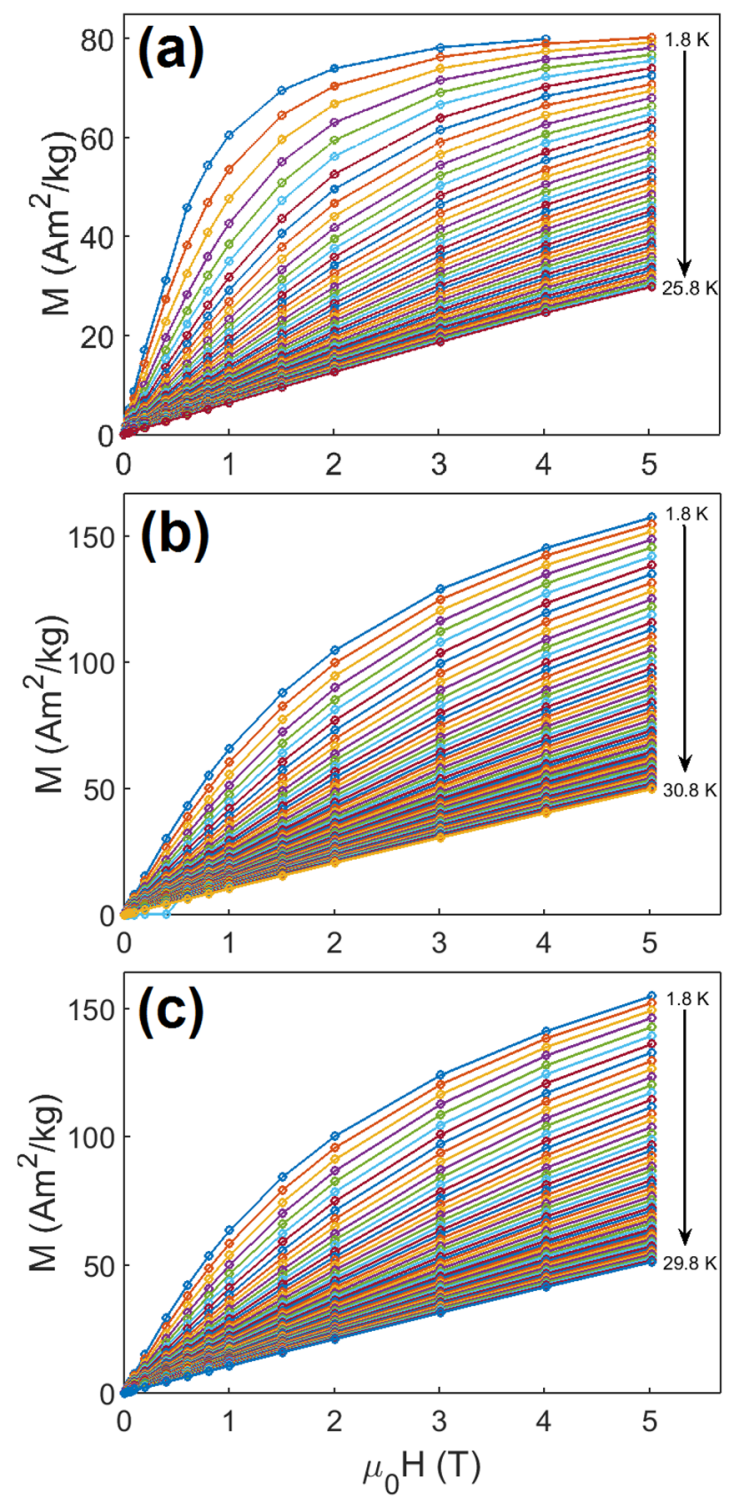

Figure 2. Isothermal magnetization data of studied compounds up to applied field of $5 \mathrm{~T}$ obtained at temperature range $1.8 \mathrm{~K}-29.8 \mathrm{~K}$ with the step $1 \mathrm{~K}$ for compounds $\mathbf{1}(\mathbf{a}), \mathbf{2}(\mathbf{b})$ and $\mathbf{3}(\mathbf{c})$.

and MOF-76(Gd)- $\mathrm{H}_{2} \mathrm{O}$. Besides this, dominant paramagnetic behavior in all studied compounds can be confirmed from temperature and field dependence of magnetization, see Fig. S5 in ESI. The determined magnetic parameters are summarized in Table S3 in ESI. The ferromagnetic behavior in gadolinium based metal-organic framework was observed e.g. in MOF prepared by the reaction of $\mathrm{H}_{2} \mathrm{EDA}$ ligand $\left(\mathrm{H}_{2} \mathrm{EDA}=(\text { ethylenedithio }) \text { acetic acid }\right)^{28}$, where density functional theory calculations showed that the ferromagnetic properties originated from the $4 \mathrm{f}$ electrons of Gd(III) propagating by a super-exchange pathway on two $-1+1-$ spin nets of the carboxylate groups ${ }^{28}$. The parameters of the exchange interactions calculated for our three samples 1-3 achieve values of $\mathrm{J} / \mathrm{k}_{\mathrm{B}}=0.3 \mathrm{~K}$ for MOF-76(Gd)-DMF, $\mathrm{J} / \mathrm{k}_{\mathrm{B}}=-1.8 \mathrm{~K}$ for MOF-76(Gd), and $\mathrm{J} / \mathrm{k}_{\mathrm{B}}=-1.06 \mathrm{~K}$ for MOF-76(Gd)- $\mathrm{H}_{2} \mathrm{O}$. The values of parameters of the exchange interactions for samples 1-3 sensitively reflect on different distances between Gd...Gd ions in the framework of the samples: $4.718 \AA$ for MOF-76(Gd)-DMF - compound 1, $4.296 \AA$ for MOF-76(Gd) - compound 2, and $4.326 \AA$ for MOF-76(Gd)- $\mathrm{H}_{2} \mathrm{O}$ - compound 3. This suggests, that the solvent exchange, which affects the distance between neighboring Gd ions in the framework, has a significant effect on magnetic properties and thus the possibility of influencing the parameters of the magnetocaloric phenomenon by different solvents can be expected. To evaluate the magnetocaloric effect (MCE), isothermal magnetization from 1.8 to $30 \mathrm{~K}$ was measured for the compounds $\mathbf{1}, 2$ and 3, see Fig. 2.

The relationship between magnetization changes and magnetic entropy can be expressed by Maxwell relation $(\partial M / \partial T)_{H}=(\partial S / \partial H)_{T}^{29}$, which for an isothermal-isobaric process after integration yields Eq. $1^{30,31}$ expressed as:

$$
\Delta S_{M}=\int\left(\frac{\partial M}{\partial T}\right)_{H} d H .
$$



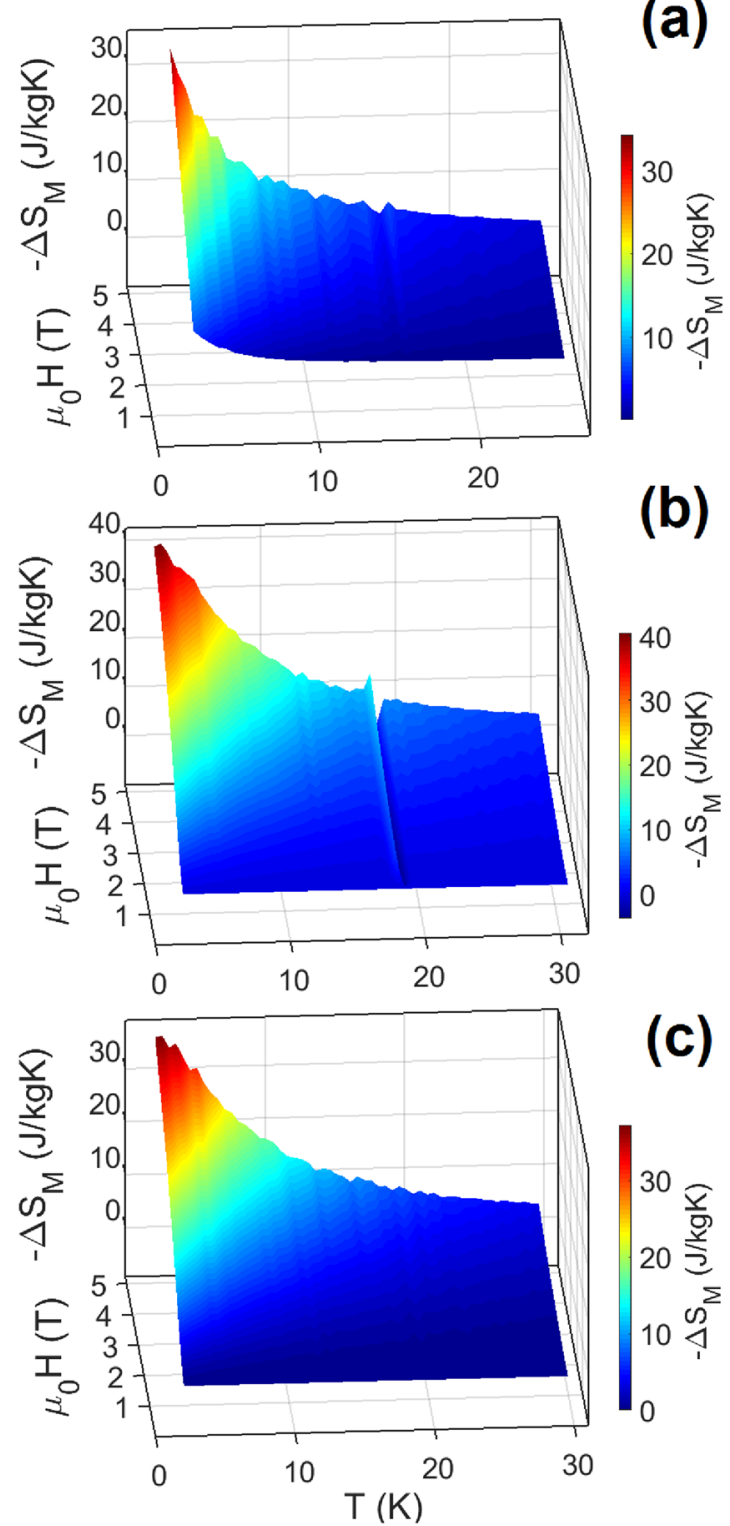

Figure 3. Magnetic entropy change $v s$. temperature of studied compounds up to applied field of $5 \mathrm{~T}$ calculated from isothermal magnetization data. 3D view on $-\Delta S_{M}$ evolution for $\mathbf{1}(\mathbf{a}), \mathbf{2}(\mathbf{b})$ and $\mathbf{3}(\mathbf{c})$.

As it is known, the magnetic entropy change $-\Delta S_{M}$ can be obtained from the experimental magnetization data at various magnetic fields and temperatures from the Maxwell equation, Eq. 1. The results of $-\Delta S_{M}$ calculated from experimental data at different magnetic fields and temperatures are given in Fig. 3. With the aim to estimate the magnetocaloric properties of studied samples 1-3 via magnetic entropy change, the isothermal magnetization data recorded by standard measurement protocol was applied. The details of standard protocol are described in ESI.

The $-\Delta S_{M}(T)$ value shows a gradual increase with increasing $\Delta \mathrm{H}$ and decreasing temperature, giving $-\Delta \mathrm{S}_{\mathrm{Mpk}}(\mathrm{T})=31 \mathrm{~J} \mathrm{~kg}^{-1} \mathrm{~K}^{-1}$ for MOF-76(Gd)-DMF, $-\Delta \mathrm{S}_{\mathrm{Mpk}}(\mathrm{T})=42 \mathrm{~J} \mathrm{~kg}^{-1} \mathrm{~K}^{-1}$ for MOF-76(Gd) and $\Delta \mathrm{S}_{\mathrm{Mpk}}(\mathrm{T})=38 \mathrm{~J} \mathrm{~kg}^{-1} \mathrm{~K}^{-1}$ for MOF-76(Gd)- $\mathrm{H}_{2} \mathrm{O}$ at an applied field change of $5 \mathrm{~T}\left(-\Delta \mathrm{S}_{\mathrm{Mpk}}=\right.$ peak of magnetic entropy change). At a first sight, the value of $-\Delta \mathrm{S}_{\mathrm{Mpk}}$ changes with the different distances between $\mathrm{Gd} \cdots \mathrm{Gd}$ ions in the framework of the samples: $4.718 \AA$ for MOF-76(Gd)-DMF, $4.296 \AA$ for MOF-76(Gd) and $4.326 \AA$ for MOF$76(\mathrm{Gd})-\mathrm{H}_{2} \mathrm{O}$. However, we can obtain different view based on the formula $\Delta \mathrm{S}_{\mathrm{M}}=\mathrm{nR} \ln (2 \mathrm{~s}+1) / \mathrm{M}_{\mathrm{w}}$ (where $\mathrm{R}$ is the gas constant and s represents the effective spin, $\mathrm{M}_{\mathrm{w}}$ is a molar weight of the sample and $n$ is a number of noninteracting spins). The theoretical maximum entropy value per mole, $-\Delta \mathrm{S}_{\mathrm{M}}$, for isotopic $\mathrm{Gd}^{3+}$ ion with seven unpaired $4 \mathrm{f}$ electrons and spin $s=7 / 2$, the corresponding to $\mathrm{n}=1$, is $109.9 \mathrm{~J} \cdot \mathrm{kg}^{-1} \cdot \mathrm{K}^{-132-35}$. For the MOF compounds, where the molar mass is larger due to presence of organic ligands, the maximal theoretical entropy change calculated using this formula is lower. Therefore it is necessary to expect other (lower) $\Delta S$ values than calculated according to the above mentioned theoretical equation. Calculated maximal entropy change for the compound 1, $\left\{\left[\mathrm{Gd}(\mathrm{BTC})\left(\mathrm{H}_{2} \mathrm{O}\right)\right] \cdot \mathrm{DMF}\right\}_{\mathrm{n}}$, is $37.9 \mathrm{~J} \cdot \mathrm{kg}^{-1} \cdot \mathrm{K}^{-1}$, for the compound $2,\{[\mathrm{Gd}(\mathrm{BTC})]\}_{\mathrm{n}}$, the theoretical 


\begin{tabular}{|c|c|c|c|c|c|c|}
\hline Compound & Linker & ID & $\mathrm{d} / \AA ̊ \AA$ & $\mathbf{M} / \mathbf{T}$ & $\begin{array}{l}-\Delta \mathrm{S}_{\mathrm{M}} / \mathrm{J} \\
\mathrm{kg}^{-1} \cdot \mathrm{K}^{-1}\end{array}$ & Ref. \\
\hline MOF-76(Gd)-DMF $\{[\mathrm{Gd}(\mathrm{BTC})(\mathrm{DMF})]\}_{\mathrm{n}}$ & trimesate (BTC) & $1 \mathrm{D}$ & 4.718 & 5 & 31 & [this work] \\
\hline MOF-76(Gd) $\{[\mathrm{Gd}(\mathrm{BTC})]\}_{\mathrm{n}}$ & trimesate (BTC) & $1 \mathrm{D}$ & 4.296 & 5 & 42 & [this work] \\
\hline MOF-76(Gd)- $\mathrm{H}_{2} \mathrm{O}\left\{\left[\mathrm{Gd}(\mathrm{BTC})\left(\mathrm{H}_{2} \mathrm{O}\right)\right] \cdot 4 \mathrm{H}_{2} \mathrm{O}\right\}_{\mathrm{n}}$ & trimesate $(\mathrm{BTC})$ & $1 \mathrm{D}$ & 4.326 & 5 & 38 & [this work] \\
\hline $\multirow{2}{*}{[\mathrm{Gd}(\mathrm{FOR})(\mathrm{BDC})]}_{\mathrm{n}}$ & \multirow{2}{*}{$\begin{array}{l}\text { formate (FOR) } \\
\text { terephthalate (BDC) }\end{array}$} & \multirow{2}{*}{$2 \mathrm{D}$} & \multirow{2}{*}{3.957} & 5 & 42 & \multirow{2}{*}{36} \\
\hline & & & & 3 & 34 & \\
\hline $\multirow{2}{*}{\left[\mathrm{Gd}(\mathrm{FOR})_{3}\right]}_{\mathrm{n}}$ & \multirow{2}{*}{ formate (FOR) } & \multirow{2}{*}{$3 \mathrm{D}$} & \multirow{2}{*}{3.987} & 7 & 56 & \multirow{2}{*}{37} \\
\hline & & & & 3 & 50 & \\
\hline$\left\{\left[\mathrm{Gd}(\mathrm{PDA})(\mathrm{OX})_{0.5}\left(\mathrm{H}_{2} \mathrm{O}\right)_{2}\right]\right\}_{\mathrm{n}}$ & $\begin{array}{l}\text { oxalate }(\mathrm{OX}) \\
\text { propandionate }(\mathrm{PDA})\end{array}$ & $2 \mathrm{D}$ & 4.588 & 5 & 44 & 38 \\
\hline$\left\{\left[\left[\mathrm{Gd}_{2}(\mathrm{FUM})_{3}\left(\mathrm{H}_{2} \mathrm{O}\right)_{4}\right] \cdot 3 \mathrm{H}_{2} \mathrm{O}\right\}_{\mathrm{n}}\right.$ & fumarate (FUM) & OD & 4.588 & 5 & 21 & 43 \\
\hline$\left\{\left[\mathrm{Gd}_{2}(\mathrm{~N}-\mathrm{BDC})_{3}(\mathrm{DMF})_{4}\right]\right\}_{\mathrm{n}}$ & 2-aminoterephthalate (N-BDC) & OD & 4.120 (dimer) & 7 & 29 & 44 \\
\hline$\left\{\left[\mathrm{Gd}_{2}(\mathrm{IDA})_{3}\right] \cdot 2 \mathrm{H}_{2} \mathrm{O}\right\}_{\mathrm{n}}$ & iminodiacetate (IDA) & $2 \mathrm{D}$ & 3.840 & 5 & 37 & 45,46 \\
\hline
\end{tabular}

Table 1. Selected gadolinium 3D polymeric frameworks build from carboxylic acids with corresponding magnetic entropy changes $\left(-\Delta \mathrm{S}_{\mathrm{M}}\right)$ measured at different magnetic fields and $\mathrm{T}=1.8 \mathrm{~K}$. ID - ion dimensionality - propagation of gadolinium (III) ions only via carboxylate group. $\left(\mathrm{COO}^{-}\right), \mathrm{d}$ - the shortest $\mathrm{Gd} \cdots \mathrm{Gd}$ distance.

value is $47.5 \mathrm{~J} \cdot \mathrm{kg}^{-1} \cdot \mathrm{K}^{-1}$ and for the compound $3,\left\{\left[\mathrm{Gd}(\mathrm{BTC})\left(\mathrm{H}_{2} \mathrm{O}\right)\right] \cdot 4 \mathrm{H}_{2} \mathrm{O}\right\}_{\mathrm{n}}$, the theoretical value is $38.0 \mathrm{~J} \cdot \mathrm{kg}^{-1}$. $\mathrm{K}^{-1}$. Apparently, in our study the highest value $\Delta \mathrm{S}_{\mathrm{Mpk}}(\mathrm{T})$ was observed for compound $2\left(\Delta \mathrm{S}_{\mathrm{Mpk}}(\mathrm{T})=42 \mathrm{Jkg}^{-1} \mathrm{~K}^{-1}\right.$ at $1.8 \mathrm{~K}$ for $\Delta \mathrm{H}=5 \mathrm{~T})$. This value does not reach the theoretical one $\left(47.5 \mathrm{~J} \mathrm{~kg}^{-1} \mathrm{~K}^{-1}\right)$.

In general, the difference between measured and theoretical values mainly originates from the magnetic interactions and crystal-field effects. The coupling between $\mathrm{Gd}^{3+}$ ions as well as their finite magnetic anisotropies, reduce the achievable entropy content. The lower experimental values were also observed for compound $\mathbf{1}$, but no discrepancy between calculated and measured values was observed in sample 3. The $\Delta \mathrm{S}_{\mathrm{Mpk}}(\mathrm{T})$ for the compounds 1, 2 and 3 reached 81.8, 88.4 and 100\% of the theoretical values, respectively. This suggests that in compound 3 $\mathrm{Gd}^{3+} \ldots \mathrm{Gd}^{3+}$ antiferromagnetic interactions (see Fig. S5 and Table S3 in ESI) are decoupled gradually and higher fields promote a larger decoupling between the individual spin centers, yielding an increasingly much better agreement and entropy to approaches the maximum value for fully decoupled, non-interacting single-ion spins. It should be emphasized that the nature of the interactions (which originate from the Curie Law) between Gd ions in studied MOFs compounds may be antiferromagnetic, but these interactions are upset above the Néel temperature and hence the system is in a paramagnetic state. Therefore no inverse MCE is expected.

The observed values $\Delta \mathrm{S}_{\mathrm{Mpk}}(\mathrm{T})$ are comparable to other Gd-MOF compounds. A list of selected 3D MOFs based on gadolinium (III) with magnetic entropy changes at various applied field change magnitudes and temperature $2 \mathrm{~K}$ are presented in Table 1 . It is to note, that the entropy changes in carboxylate MOFs mainly depends on the position and interconnection of magnetically active centers in final crystal structure, which are modulated by the several factors such as gadolinium distance, bulkiness of the ligand or ion dimensionality (ID). ID expresses the spatial spreading of Gd(III) ions bridged only by carboxylate group of linker. The higher dimensionality usually leads to higher the entropy change (see Tab. 1). Compound $\{[\mathrm{Gd}(\mathrm{HCOO})(\mathrm{BDC})]\}_{\mathrm{n}}(\mathrm{BDC}=$ terephthalate, $\mathrm{FOR}=$ formate $=\mathrm{HCOO}$ ) is structurally similar to MOF-76(Gd)-X (see Fig. S6 in ESI). The crystal structure of $\{[\mathrm{Gd}(\mathrm{FOR})(\mathrm{BDC})]\}_{\mathrm{n}}$ is formed by $\mathrm{Gd}^{3+}$ ions bridged by $\mathrm{HCOO}$ to form a $2 \mathrm{D}$ plains, which are further pillared with BDC linkers. Complex exhibits maximum entropy change of $47 \mathrm{~J}^{-\mathrm{kg}^{-1}} \cdot \mathrm{K}^{-1}$ at $2.3 \mathrm{~K}$ and $\Delta \mathrm{H}=9 \mathrm{~T}^{36}$. Another comparison can be performed with $3 \mathrm{D}$ polymer $\left\{\left[\mathrm{Gd}(\mathrm{FOR})_{3}\right]\right\}_{\mathrm{n}}$ in which $\mathrm{Gd}(\mathrm{III})$ ions are triangularly arranged by formates in magnetically frustrated lattice ${ }^{37}$. Formate as the smallest and the simplest carboxylate molecule led to formation of framework with 3D ion dimensionality with short Gd...Gd distance of 3.988 $\AA$. The combination of all three aspects short Gd...Gd distance, small linker and high dimensionality of metal centers resulted in the highest entropy change $56 \mathrm{~J} \cdot \mathrm{kg}^{-1} \cdot \mathrm{K}^{-1}$ observed for gadolinium-based MOFs. Despite of the fact that MOF-76(Gd) represents material with $1 \mathrm{D}$ ion dimensionality, observed entropy change $42 \mathrm{~kJ} \cdot \mathrm{kg}^{-1} \cdot \mathrm{K}^{-1}$ is typical for materials with higher ID, such as $\{[\mathrm{Gd}(\mathrm{HCOO})(\mathrm{BDC})]\}_{\mathrm{n}}{ }^{36}$ or $\left\{\left[\mathrm{Gd}(\mathrm{PDA})(\mathrm{OX})_{0.5}\left(\mathrm{H}_{2} \mathrm{O}\right)_{2}\right]\right\}_{\mathrm{n}}{ }^{38}$.

For further investigation of magnetic properties, the Arrott plots in the vicinity of critical temperature for compounds 1-3 were drawn and are shown in Fig. S7 in ESI. According to the Banerjee criterion, the positive slope of $\mu_{0} \mathrm{H} / \mathrm{M}$ vs. $\mathrm{M}^{2}$ indicates a presence of second order magnetic phase transition ${ }^{39,40}$. The parameters $\mathrm{A}(\mathrm{T})$ and $\mathrm{B}(\mathrm{T})$ obtained from the linear region of the Arrott plots are shown in Fig. S8 in ESI. As is obvious from Fig. S7, there is no change in the slope of Arrott curves, thus we can conclude that there is no second-order phase transition present in all studied system in the examined temperature interval $(1.8-30 \mathrm{~K})$.

To study and confirm the magnetocaloric effect by another way the specific heat capacity measurements were realized. We have investigated the compound 2 , the sample with largest $-\Delta S_{M}$, by the temperature-dependent heat capacities $(C)$ measurements at different external magnetic fields (0-9T), see Fig. 4a. From the obtained C values it followed that the magnetic contribution dominated at lower temperatures (see Fig. 4a). At higher temperatures, the non-magnetic contributions due to thermal vibrations of lattice prevailed. The value of magnetic entropy change $\Delta S$ of the studied compound 2 , see Fig. $4 \mathrm{~b}$, was obtained from the heat capacity data by equation $\mathrm{S}_{\mathrm{M}}=\int \mathrm{C}_{\mathrm{M}} / \mathrm{T} \mathrm{dT}$, where the magnetic heat capacity $\mathrm{C}_{\mathrm{M}}$ was obtained by subtracting the lattice contribution from the total specific heat determined experimentally. The obtained value of magnetic entropy $39.5 \mathrm{~J} \mathrm{~kg}^{-1} \mathrm{~K}^{-1}$ at $1.8 \mathrm{~K}$ for magnetic field change of $5 \mathrm{~T}$ is in good agreement with magnetization measurements, derived from the magnetization data $\left(42 \mathrm{~J} \mathrm{~kg}^{-1} \mathrm{~K}^{-1}\right.$ at $\left.1.8 \mathrm{~K}\right)$. The other magnetocaloric parameter, the adiabatic temperature 

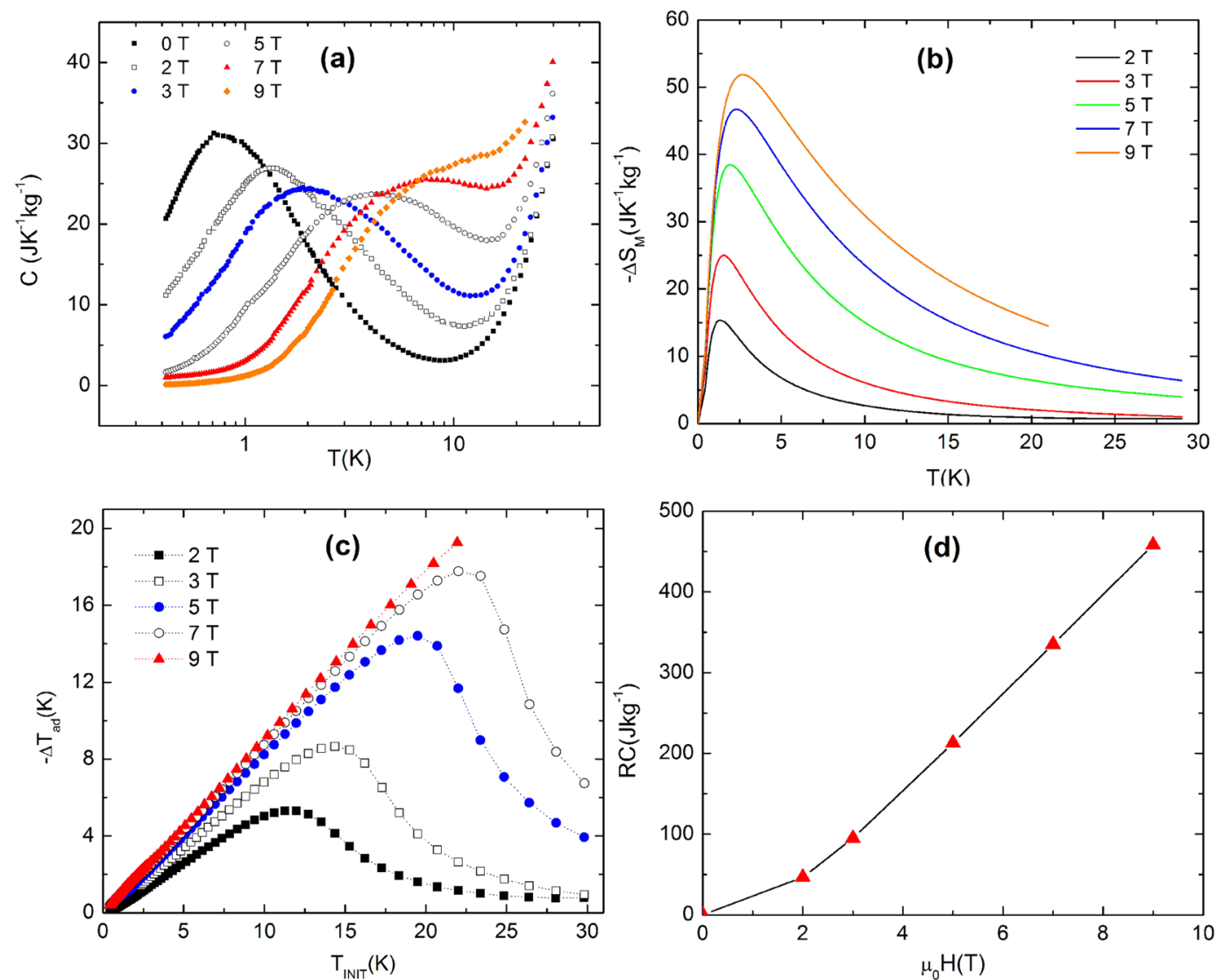

Figure 4. Magnetocaloric response in compound 2 studied via heat capacity measurements at temperatures $0.4 \mathrm{~K}-30 \mathrm{~K}$ : (a) heat capacity in constant magnetic fields of $0,2,3,5,7,9 \mathrm{~T}$, (b) the magnetic entropy change calculated from the heat capacity data after substraction of lattice contribution, (c) adiabatic temperature change as a function of temperature at various changes of applied magnetic field, (d) calculated parameter relative cooling power RCP.

change, $-\Delta \mathrm{T}_{\mathrm{ad}}$ (see Fig. $4 \mathrm{c}$ ), was estimated as a function of the initial temperature during the adiabatic change from non-zero initial magnetic field, to zero magnetic field ${ }^{41}$. As it is demonstrated on Fig. $4 \mathrm{c}$, the $-\Delta \mathrm{T}_{\mathrm{ad}} v s$. initial temperature dependences are characterized by a maximum, which is shifted to higher temperatures in higher magnetic fields. For example, the maximal values of adiabatic temperature change $-\Delta \mathrm{T}_{\mathrm{ad}}$ at the proximity of $\mathrm{T}_{\text {init }} \sim 23 \mathrm{~K}$ increase from $-\Delta \mathrm{T}_{\mathrm{ad}}=11 \mathrm{~K}$ for $\Delta \mathrm{H}=1 \mathrm{~T}$ to $-\Delta \mathrm{T}_{\mathrm{ad}}=18 \mathrm{~K}$ for $\Delta \mathrm{H}=7 \mathrm{~T}$. This demonstrates the excellent properties of the studied system 2 with regard to its use as a potential refrigerant for magnetic cooling at low temperatures. Also, it is necessary to note, that from experimental study is evident that in studied system no first order phase transition was observed and therefore only magnetic subsystem is responsible for existence of magnetic entropy change.

Suitable parameter for the characterization of the MCE is the relative cooling power (RCP), and it can be estimated from temperature dependence of magnetic entropy change ${ }^{42}$. RCP is defined as: $R C P(\Delta H)=\int_{T_{\text {cold }}}^{T_{\text {hot }}}-\Delta S_{M}(T, \Delta H) d T$, where $\Delta \mathrm{H}$ is the difference between the applied fields, $\mathrm{T}_{\text {cold }}$ and $\mathrm{T}_{\text {hot }}$ are the temperatures of reservoirs, $-\Delta \mathrm{S}_{\mathrm{M}}$ is magnetic entropy change. RCP parameter is thus the measure of the energy that can be transferred between the hot and cold reservoirs. The calculated RCP values for compound 2 , with highest value of magnetic entropy change, have been found in the range of $50 \mathrm{~J} \mathrm{~kg}^{-1}-460 \mathrm{~J} \mathrm{~kg}^{-1}$ with increasing magnetic field from $2 \mathrm{~T}-9 \mathrm{~T}$, see Fig. $4 \mathrm{~d}$.

\section{Conclusions}

The effect of presence/absence of solvent molecules in channel system of MOF-76(Gd) on structural and magnetic properties was investigated. Magnetic studies suggest the presence of ferromagnetic couplings between the intrachain $\mathrm{Gd}(\mathrm{III})$ ions and large magnetocaloric effects (MCEs) with $-\Delta S_{\max }=32 \mathrm{~J} \cdot \mathrm{kg}^{-1} \cdot \mathrm{K}^{-1}$ (MOF-76(Gd)-DMF), $41 \mathrm{~J} \cdot \mathrm{kg}^{-1} \cdot \mathrm{K}^{-1}$ (MOF-76(Gd)) and $38 \mathrm{~J} \cdot \mathrm{kg}^{-1} \cdot \mathrm{K}^{-1}\left(\mathrm{MOF}-76(\mathrm{Gd})-\mathrm{H}_{2} \mathrm{O}\right)$ under $5 \mathrm{~T}$ applied field. Observed results could be attributed to different distances between $\mathrm{Gd} \cdots \mathrm{Gd}$ ions in the framework of the samples: $4.718 \AA$ for MOF-76(Gd)-DMF, 4.296 $\AA$ for MOF-76(Gd) and 4.326 $\AA$ for MOF-76(Gd)- $\mathrm{H}_{2} \mathrm{O}$ caused by solvent exchange effect. Heat capacity measurements confirmed the value of magnetic entropy $S$ obtained from the magnetization data. The studied three metal-organic frameworks can be considered as an attractive candidate as cryogenic magnetorefrigerants. 
Received: 4 July 2019; Accepted: 23 September 2019;

Published online: 30 October 2019

\section{References}

1. Ram, N. R. et al. Review on Magnetocaloric Effect and Materials. J. Supercond. Nov. Magn. 31, 1971-1979 (2018).

2. Si, Y. et al. Magnetostructural transformation and magnetocaloric effect of Sn-bonded $\mathrm{Mn}_{0.66} \mathrm{Fe}_{0.34} \mathrm{Ni}_{0.66} \mathrm{Fe}_{0.34} \mathrm{Si}_{0.66} \mathrm{Ge}_{0.34} \mathrm{Composite}_{\text {. }}$ Sci. Rep. 8, 19, https://doi.org/10.1038/s41598-017-18240-xID (2018).

3. Phan, M. H. \& Yu, S. C. Review of the magnetocaloric effect in manganite materials. J. Magn. Magn. Mater. 308, 325-340 (2007).

4. Biswas, S., Adhikary, A., Goswami, S. \& Konar, S. Observation of a large magnetocaloric effect in a 2D Gd(III)-based coordination polymer. Dalton Trans. 42, 13331-13334 (2013).

5. Pecharsky, V. K. \& Gschneidner, K. A. Jr. Giant Magnetocaloric Effect in $\mathrm{Gd}_{5}\left(\mathrm{Si}_{2} \mathrm{Ge}_{2}\right)$. Phys. Rev. Lett. 78, 4494 (1997).

6. Zheng, Y. Z., Zhou, G. J., Zheng, Z. \& Winpenny, R. E. P. Molecule-based magnetic coolers. Chem. Soc. Rev. 43, 1462-1475 (2014).

7. Zhou, G. J., Richter, J., Schnack, J. \& Zheng, Y. Z. Hydrophobicity-Driven Self-Assembly of an Eighteen-Membered Honeycomb Lattice with Almost Classical Spins. Chem. Eur. J. 42, 14846-14850 (2016).

8. Wang, Y. et al. High-performance low-temperature magnetic refrigerants made of gadolinium-hydroxy-chloride. J. Mater. Chem. C. 4, 6473-6477 (2016).

9. Chen, W. P. et al. A Mixed-Ligand Approach for a Gigantic and Hollow Heterometallic Cage $\left\{\mathrm{Ni}_{64} \mathrm{RE}_{96}\right\}$ for $\mathrm{Gas}_{\mathrm{Separation}}$ and Magnetic Cooling Applications. Angew. Chem. 55, 9375-9379 (2016).

10. Qin, L. et al. Topological Self-Assembly of Highly Symmetric Lanthanide Clusters: A Magnetic Study of Exchange-Coupling "Fingerprints" in Giant Gadolinium(III) Cages. J. Am. Chem. Soc. 139, 16405-16411 (2017).

11. Hou, Y. L. et al. Unique $(3,12)$-connected coordination polymers displaying high stability, large magnetocaloric effect and slow magnetic relaxation. Chem. Commun. 49, 6066-6068 (2013).

12. Rosi, N. L. et al. Rod Packings and Metal-Organic Frameworks Constructed from Rod-Shaped Secondary Building Units. J. Am. Chem. Soc. 127, 1504-1518 (2005).

13. Jiang, H. L., Tsumori, N. \& Xu, Q. A Series of $(6,6)$-Connected Porous Lanthanide-Organic Framework Enantiomers with High Thermostability and Exposed Metal Sites: Scalable Syntheses, Structures, and Sorption Properties. Inorg. Chem. 49, 10001-10006 (2010).

14. Almáši, M., Zeleňák, V., Opanasenko, M. \& Císařová, I. Ce(III) and Lu(III) metal-organic frameworks with Lewis acid metal sites: Preparation, sorption properties and catalytic activity in Knoevenagel condensation. Catal. Today. 243, 184-194 (2015).

15. Gustafsson, M. et al. Family of Highly Stable Lanthanide Metal-Organic Frameworks: Structural Evolution and Catalytic Activity. Chem. Mater. 22, 3316-3320 (2010).

16. Chen, B. et al. Luminescent Open Metal Sites within a Metal-Organic Framework for Sensing Small Molecules. Adv. Mater. 19, $1693-1696$ (2007).

17. Xie, L. H. et al. Crystallographic studies into the role of exposed rare earth metal ion for guest sorption. CrystEngComm. 13, 5849-5857 (2011).

18. Chen, B., Wang, L., Zapata, F., Qian, G. \& Lobkovsky, E. B. A Luminescent Microporous Metal-Organic Framework for the Recognition and Sensing of Anions. J. Am. Chem. Soc. 130, 6718-6719 (2008).

19. Guo, X. et al. A lanthanide metal-organic framework with high thermal stability and available Lewis-acid metal sites. Chem. Commun. 30, 3172-3174 (2006).

20. Li, Z. \& Liu, K. Crystal structure of aqua(benzene-1,3,5-tricarboxylato)-lutetium(III), $\mathrm{Lu}\left(\mathrm{H}_{2} \mathrm{O}\right)\left(\mathrm{C}_{9} \mathrm{H}_{3} \mathrm{O}_{6}\right)$. Z. Kristallogr. - New Cryst. Struct. 227, 91-92 (2012).

21. Ethiraj, J. et al. Solvent-Driven Gate Opening in MOF-76-Ce: Effect on $\mathrm{CO}_{2}$ Adsorption. ChemSusChem. 9, 713-719 (2016).

22. Chevinly, A. S., Mobtaker, H. G., Yousefi, T., Shirani, A. S. \& Aghayan, H. $\left\{\left[\mathrm{Ce}(\mathrm{BTC})\left(\mathrm{H}_{2} \mathrm{O}\right)\right] \cdot \mathrm{DMF}\right\}_{\mathrm{n}}$ metal organic framework as a new adsorbent for removal of neodymium ions. Inorg. Chim. Acta. 455, 34-40 (2017).

23. Lorusso, G. et al. Dense Metal-Organic Framework for Enhanced Magnetic Refrigeration. Adv. Mater. 25, 4653-4656 (2013).

24. Yang, J. et al. Structures, Photoluminescence, Up-Conversion, and Magnetism of 2D and 3D Rare-Earth Coordination Polymers with Multicarboxylate Linkages. Inorg. Chem. 45, 2857-2865 (2006).

25. Zhou, Q. et al. Reversible switching of slow magnetic relaxation in a classic lanthanide metal-organic framework system. Chem. Commun. 49, 8244-8246 (2013).

26. Almáši, M., Zeleňák, V., Kuchár, J., Bourrelly, S. \& Llewellyn, P. L. New members of MOF-76 family containing Ho(III) and Tm(III) ions: Characterization, stability and gas adsorption properties. Colloids Surf. A. 496, 114-124 (2016).

27. Almáši, M., Zeleňák, V., Zukal, A., Kuchár, J. \& Čejka, J. A novel zinc(II) metal-organic framework with a diamond-like structure: Synthesis, study of thermal robustness and gas adsorption properties. Dalton Trans. 45, 1233-1242 (2016).

28. Zhuang, G. et al. Synthesis, properties, and magnetism-structure relationship of lanthanide-based metal-organic frameworks with (ethylenedithio)acetic acid. CrystEngComm. 16, 6963-6970 (2014).

29. Callen, H. B. Thermodynamics and an Introduction to Thermostatistics, 2nd Edition, Wiley, New York (1985).

30. Peng, J. B. et al. High-Nuclearity 3d-4f Clusters as Enhanced Magnetic Coolers and Molecular Magnets. J. Am. Chem. Soc. 134, 3314-3317 (2012).

31. Evangelisti, M. \& Brechin, E. K. Recipes for enhanced molecular cooling. Dalton Trans. 39, 4672-4676 (2010).

32. Chang, L. X., Xiong, G., Wang, L., Cheng, P. \& Zhao, B. A 24-Gd nanocapsule with a large magnetocaloric effect. Chem. Commun. 49, 1055-1057 (2013).

33. Chen, Y. C. et al. Study of a magnetic-cooling material $\mathrm{Gd}(\mathrm{OH}) \mathrm{CO}_{3}$. J. Mater. Chem. A. 25, 9851-9858 (2014).

34. Yang, Y., Zhang, Q. C., Pan, Y. Y., Long, L. S. \& Zheng, L. S. Magnetocaloric effect and thermal conductivity of Gd(OH) ${ }_{3}$ and $\mathrm{Gd}_{2} \mathrm{O}(\mathrm{OH})_{4}\left(\mathrm{H}_{2} \mathrm{O}\right)_{2}$. Chem. Comm. 51, 7317-7320 (2015).

35. Chen, W. P. et al. Quantum Monte Carlo simulations of a giant $\left\{\mathrm{Ni}_{21} \mathrm{Gd}_{20}\right\}$ cage with a $\mathrm{S}=91$ spin ground state. Nat. Commun. 9 , 2107, https://doi.org/10.1038/s41467-018-04547-4ID (2018).

36. Sibille, R., Mazet, T., Malaman, B. \& François, M. A Metal-Organic Framework as Attractive Cryogenic Magnetorefrigerant. Chem.-Eur. J. 18, 12970-12973 (2012).

37. Almáši, M., Zeleňáková, A., Císařová, I., Bednarčík, J. \& Zeleňák, V. Magnetic and Structural Studies into the Effect of Solvent Exchange Process in Metal-Organic Framework MOF-76(Gd). Acta Phys. Pol. A. 126, 308-310 (2014).

38. Liu, S. J. et al. Temperature and vapor induced reversible single-crystal-to-single-crystal transformations of three $2 \mathrm{D} / 3 \mathrm{D}$ GdIII-organic frameworks exhibiting significant magnetocaloric effects. Dalton Trans. 46, 64-70 (2017).

39. Si, X., Zhou, K., Zhang, R., Liu, Y. \& Qi, J. Magnetic phase transition and magnetocaloric properties of Mn ${ }_{1-\mathrm{x}} \mathrm{Sn}_{\mathrm{x}} \mathrm{CoGe}_{\mathrm{alloys}}$ Physics Letters A. 381, 1693-1700 (2017).

40. Chen, X. \& Zhuang, Y. Critical scaling analysis of the long-range magnetic interactions and renormalization of magnetic entropy change in $\mathrm{Gd}_{12} \mathrm{Co}_{7}$ compound. Solid State Communications. 260, 23-29 (2017).

41. Drulis, H., Hackemer, A., Folick, L. \& Zaleski, A. Magnetocaloric effect in terbium dihydrides: Heat capacity measurements. Solid State Comm. 150, 164-167 (2010).

42. Franco, V. \& Conde, A. Magnetic refrigerants with continuous phase transitions: Amorphous and nanostructured materials. Scripta Materialia. 67, 594-599 (2012). 
43. Sedláková, L. et al. Magnetism and magnetocaloric effect in $\mathrm{S}=7 / 2$ Heisenberg antiferromagnet $\mathrm{Gd}_{2}(\mathrm{fum})_{3}\left(\mathrm{H}_{2} \mathrm{O}\right)_{4} \cdot 3 \mathrm{H}_{2} \mathrm{O}$. J. Alloys Comp. 487, 425-429 (2009).

44. Lorusso, G. et al. Increasing the dimensionality of cryogenic molecular coolers: Gd-based polymers and metal-organic frameworks. Chem. Commun. 48, 7592-7594 (2012).

45. Black, C. A. et al. 3-D Lanthanide Metal-Organic Frameworks: Structure, Photoluminescence, and Magnetism. Inorganic Chemistry 48, 1062-1068 (2009)

46. Jia, J. M. et al. 3D Gd ${ }^{\mathrm{III}}$ Complex Containing $\mathrm{Gd}_{16}$ Macrocycles Exhibiting Large Magnetocaloric Effect. Cryst. Growth Des. 13, 4631-4634 (2013).

\section{Acknowledgements}

This work was supported by the by the VEGA project No. 1/0745/17 and by the Slovak Research and Development Agency under the contract APVV-15-0520.

\section{Author contributions}

V.Z. and A.Z. conceived and designed the study. M.A. prepared the samples. M.A. and V.Z. made structural, spectral and thermal characterization of the compounds. A.Z. and P.H. performed magnetic measurements and their evaluation. A.Z. and R.T. realized heat capacity measurements. S.B. and P.L. measured and evaluated gas adsorption over the samples. V.Z., A.Z. and M.A. wrote the manuscript. M.A., P.H., A.Z. and V.Z. drawn the figures. All authors reviewed and approved the manuscript.

\section{Competing interests}

The authors declare no competing interests.

\section{Additional information}

Supplementary information is available for this paper at https://doi.org/10.1038/s41598-019-51590-2.

Correspondence and requests for materials should be addressed to V.Z.

Reprints and permissions information is available at www.nature.com/reprints.

Publisher's note Springer Nature remains neutral with regard to jurisdictional claims in published maps and institutional affiliations.

(c) (i) Open Access This article is licensed under a Creative Commons Attribution 4.0 International License, which permits use, sharing, adaptation, distribution and reproduction in any medium or format, as long as you give appropriate credit to the original author(s) and the source, provide a link to the Creative Commons license, and indicate if changes were made. The images or other third party material in this article are included in the article's Creative Commons license, unless indicated otherwise in a credit line to the material. If material is not included in the article's Creative Commons license and your intended use is not permitted by statutory regulation or exceeds the permitted use, you will need to obtain permission directly from the copyright holder. To view a copy of this license, visit http://creativecommons.org/licenses/by/4.0/.

(C) The Author(s) 2019 